\title{
The Use of Indexes of The Permanent Evaluation Committee in the Management and Systemic Planning of Institutions of Higher Education for the Improvement of Quality
}

\author{
Valdecir Bertoncello ${ }^{1,2}$ Osmar Possamai ${ }^{1}$ Edson Pacheco Paladini ${ }^{1}$ Flávio \\ Bortolozzi $^{2}$ \\ ${ }^{1}$ Universidade Federal De Santa Catarina(UFSC), Brasil \\ ${ }^{2}$ CESUMAR, Brasil
}

\begin{abstract}
Abstract” Style)
The new tools for the evaluation of Higher Education still lack the practical experience that warrants their feasibility and effective application. Current research focuses on the foregrounding, development and the establishment of a system based on a technical and dynamic development, rooted on indexes hailing from the evaluation process of Institutions of Higher Education and the official indexes of the Ministry of Education in Brazil. The system will be useful for institutions in the planning, management and systemic evaluation processes of activities developed by the IHEs. Current analysis enhances not merely the Permanent Evaluation Committee but the management and quality evaluation aspects of the IHEs, or rather, the Permanent Evaluation Committees may be a good tool for such a purpose.
\end{abstract}

Keywords: Indicators, Evaluation of Higher Education, Planning, Quality in Higher Education, Education System

\section{Introduction}

The self-evaluation of an Institution of Higher Education currently abides with the demand of the Brazilian Ministry of Education (MEC), established Parliament Act 10,861 of the 14th April 2004. It is actually an important tool for the management and systemic planning for the authorities and an efficacious instrument for directors, course coordinators and professors to detect the processes' eventual weaknesses that must be overcome and the potentialities that should be boosted up.

IHEs comprehend that institutional self-evaluation is a constant process of subsidies for quality improvement and betterment through the pinpointing of the Institution's potentialities and weaknesses. Therefore, the results obtained through an index-based self-evaluation process will be useful for rethinking the practices and seeking the most appropriate solutions for each and every situation.

Results from the employment of indexes were analyzed by the respective sectors, made public and discussed by the universities' rectors, directors, coordinators, professors and students and thus became a reference for the University academy in its process in improving teaching quality (LEHFELD, 2010). Self-evaluation results established 
parameters for decision-taking that would contribute for the excellence of institutional practice. A diagnosis for institutional evaluation brings forth:

the identification of the causes of problems and deficits;

an increase in pedagogical awareness and professional capacity of the IHEs' social body; guidance in management to define the strategy planning as from the potentialities and weaknesses at each level;

the employment of complementary information to be used as reference by the Brazilian Ministry of Education's official indexes, such as external evaluation by a committee selected by INEP; evaluation of the warrant or the renewal of warrant of undergraduate courses; evaluation of students' performance - ENADE; the Course's Preliminary Score - CPC; the Courses' General Index - IGC.

Consequently, all institutional evaluation may be understood as an indispensable tool for a bettering of teaching quality and academic service to the community. It is actually a permanent process of rethinking University practice (MAINARDES, ET. AL. 2010). Current essay proposes the foregrounding of the development and establishment of a system based on technology and dynamic development, rooted on the indexes taken from the evaluation process of the IHEs and from the official indexes of the Brazilian Ministry of Education (DIAS SOBRINHO, 2008). The system will be employed in the planning, management and systemic evaluation processes of the IHEs' activities.

\section{Case Description}

Current process has been applied to an institution which holds that the aim of the Permanent Evaluation Committee (CPA) is to evaluate all the levels in which IHEs are involved with regard to the quality of educational services. The set of evaluation tools, compatible with the new management trends, may furnish the institution with new instruments capable of furnishing relevant information in the control and search for an improvement in quality of all the services provided for to the internal community and to society by the IHE. Self-evaluation should involve the entire internal and external communities.

The proposed tool initially analyzes three groups of indexes which evaluate the IHEs through their several communities: undergraduate students, administration staff; external community. To calculate the General Index (IG), groups of indexes were defined: primary Ii, secondary - Ii,j, tertiary - Ii,j,k, up to $\mathrm{Ii}, \mathrm{j}, \mathrm{k}, \ldots, \mathrm{p}$ till $\mathrm{p}$, required to incorporate relevant information to be evaluated. The main groups of current indexes incorporated are:

Primary Index of the academic community - I1 is the set of indexes $\mathrm{I} 1, \mathrm{j}, \mathrm{k}, \ldots, \mathrm{p} 1$ representing coordinators, professors and students.

Primary Index of the technical and administrative community - I2 is the set of indexes $\mathrm{I} 2, \mathrm{j}, \mathrm{k}, \ldots, \mathrm{p} 2$ involving working conditions, motivation, satisfaction of the collaborator and self-evaluation.

Primary Index of the external community - I3 is the set of indexes $\mathrm{I} 3, \mathrm{j}, \mathrm{k}, \ldots, \mathrm{p} 3$ representing relationship, social responsibility and foresight of the IHE with regard to entrepreneurship.

Results were available in various forms: general reports on the replies by students, professors and coordinators, with regard to general and specific issues; reports on the above-mentioned answers from each undergraduate course, by area of knowledge, by first and last year university students; data were later transformed into graphs and tables and, consequently, groups of results for each 
course and evaluated level, coupled to the Institution's targets and activities for each index, were provided.

\section{Characterization of the practical situation}

Decisions within the educational environment, particularly in private institutions, are taken through conventional procedures, albeit not always technically foregrounded (HOLDEREGGER, 2009). There are several studies on indexes used in quality evaluation. Bottani \& Morrison (1998) discuss educational indexes, their aims, limits, perspectives and production processes. Tavenas (2003) investigated the reference system for indexes and evaluation procedures that contribute towards the quality factor; Mhlanga (2008) showed the composition of indexes for the administration of educational quality; Pratasavitskaya (2008) analyzed the theories on the administration of institutional quality. When the Institution understands its strong and weak factors, it intervenes for quality improvement according to its criteria and priorities. Consequently, the establishment of an automatized and dynamic system in management, control and planning, foregrounded on indexes hailing from the CPA's evaluation and the MEC's official indexes, may bring about better results in the quality of academic services and innovations in the management and planning processes of the IHEs' activities.

\section{Improvements and associated indexes}

The three index groups were: aim, justification, standard and environment. Indexes were adjusted to interval $[0 ; 100]$ for their normalization.

\subsection{Group I - Main Index of the undergraduate community - I1.}

Its aim is the functioning and acceptance level of actions related to the activitytargets of each undergraduate course in the IHE, according to the point of view of coordinators, professors and students. The justification of the above-mentioned group and of its respective secondary indexes is a requirement of the ProRectors and Directors in the quality administration of academic activities so that the negative and positive factors in each course may be identified. The group was divided into three sub-groups: coordinators, professors and students so that different points of view may be obtained on the same situation. Standard for the group and its secondary indexes consisted of attaining $80 \%$ in satisfaction and acceptance by the community. Environment is in line since it is directly linked to efficiency increase.

Secondary indexes of group 1 comprise: I1,1 - coordinators; I1,2 - professors; I1,3 - students.

I - Secondary index of coordinators - $\mathbf{I}_{1,1}$.

Aim: to identify the functioning level of actions related to target activities for each course in IHE from the point of view of the coordinators. Environment: in line, since the definition of any increase in efficiency implies in an in line improvement (PALADINI, 2011).

The group's secondary indexes for the establishment of averages are: I1,1,1 course's evaluation; I1,1,2 - evaluation of the performance of course professors; I1,1,3 - evaluation of students; I1,1,4 self-evaluation as coordinator; I1,1,5 evaluation of support given to the coordinator; I1,1,6 - evaluation of the coordination office; I1,1,7 - evaluation of the institution; I1,1,8 - number of books acquired during the year; I1,1,9 - use of the library; I1,1,10 - employment of evaluation as an instrument for the 
boosting of learning; I1,1,11 - number of institutional research projects; I1,1,12 students' fallout; I1,1,13 - temporary suspension of enrolment; I1,1,14 average number of students per discipline; I1,1,15 - number of students enrolled per class; I1,1,16 - percentage of professors with a doctoral degree; I1,1,17 percentage of professors with a Master's degree; I1,1,18 - percentage of professors paid by the hour; I1,1,19 - percentage of professors on a part-time basis; e; I1,1,20 - percentage of professors on a full-time basis.

\section{II- Secondary Index of professors - $\mathbf{I}_{1,2}$.}

Aim: to identify the functioning level of actions related to general activities for each undergraduate course in IHE from the point of view of professors. Environment: in line, since the definition of any increase in efficiency implies in an in line improvement (PALADINI, 2011).

Indexes which establish averages are: I1,2,1 - course evaluation; I1,2,2 evaluation of the course coordinator's performance; I1,2,3 - evaluation of professors' activities; I1,2,4 - evaluation of the professors' performance; I1,2,5 evaluation of the institution's infrastructure; I1,2,6 - evaluation of support given to the professor; I1,2,7 evaluation of the classroom; I1,2,8 evaluation of the students; I1,2,9 evaluation of general formation.

\section{III - Secondary Index of students - $\mathbf{I}_{1,3}$.}

Aim: to identify the satisfaction level on care and attention to students from the point of view of the students; Environment: in line, actual increase in efficiency and on line, since it establishes a relationship with the job market.

The group's tertiary indexes that establish averages are given below:

$\mathbf{I}_{1,3,1}$ - The Course's evaluation index comprises seven indexes at level 4 .
$\mathbf{I}_{1,3,1,1}$ - Index of course program and evaluation of learning.

Indexes which establish averages are: I1,3,1,1,1 - evaluation of support material (books, texts, environment of the on-line student and others), used by professors; I1,3,1,1,2 - evaluation of depth level of the contents discussed in lectures; I1,3,1,1,3 - evaluation of professors' exigency level in tests; I1,3,1,1,4 evaluation of the course's syllabus, taking into account current exigencies of the job market; I1,3,1,1,5 - evaluation of the type of the Course's Concluding Assignment; I1,3,1,1,6 - evaluation of tutorials for the Course's Concluding Assignment; I1,3,1,1,7 - evaluation of tutorials during trainee activities; I1,3,1,1,8 - evaluation of further complementary activities; I1,3,1,1,9 - evaluation of extra class disciplines (on-line material, study and class activities); I1,3,1,1,10 - evaluation of the number of technical visits.

$\mathbf{I}_{1,3,1,2}$ - Evaluation of the course with regard to the job market.

Indexes which establish averages are: I1,3,1,2,1 - evaluation of the course's acknowledgement by the job market; I1,3,1,2,2 - evaluation of the insertion and promotion within the job market with regard to the future professional trained by the IHE; I1,3,1,2,3 - evaluation of the qualification earned by the student to enter the highly competitive job market.

$\mathbf{I}_{1,3,1,3}$ - Evaluation of professors.

Indexes which establish averages are:

I1,3,1,3,1 - evaluation of teaching strategies by professors with regard to contents of lectures; I1,3,1,3,2 evaluation of professors' content versatility in lectures; I1,3,1,3,3 evaluation of professors' activities to motivate students to take an active part in the lectures and in other activities; I1,3,1,3,4 - evaluation of the links between professors and the job market or representative organs in their professional 
area; I1,3,1,3,5 - evaluation of the materialization and development of the Teaching Plan.

\section{$\mathbf{I}_{1,3,1,4}-$ Evaluation of the course's coordinator.}

Indexes which establish averages are: I1,3,1,4,1 - evaluation of the coordinator's participation in solving problems related to the course; I1,3,1,4,2 - evaluation of coordinator's activities to improve the quality of the course; I1,3,1,4,3 - evaluation of the coordinator's activities to motivate students to participate in lectures and in other activities.

\section{$\mathbf{I}_{1,3,1,5}$ - Evaluation of the} course's infrastructure.

Indexes which establish averages are: I1,3,1,5,1 - evaluation of books and journals related to the course and available at the library; I1,3,1,5,2 evaluation of laboratories, clinics and other didactic spaces used during the course; I1,3,1,5,3 - evaluation of spaces used for professional practice; I1,3,1,5,4 - evaluation of the availability of the virtual learning space (AVA) with regard to disciplines supplied by the nonpresence mode.

\section{$\mathbf{I}_{1,3,1,6}-$ Evaluation of the course as a whole.}

Indexes which establish averages are: I1,3,1,6,1 - evaluation of expectations with regard to the course during the student's first year; I1,3,1,6,2 - evaluation of expectations with regard to the course by the university-leaving student (for students from the second year onwards). I1,3,1,7 - Self-evaluation. Indexes which establish averages are: I1,3,1,7,1 evaluation of the number of hours per week devoted to studies; I1,3,1,7,2 evaluation of the number of books related to the course acquired by the student during the year; I1,3,1,7,3 - evaluation of the student's performance as a student.
I1,3,2 - Evaluation of Attendance, Infrastructure, Products and Services comprises three indexes.

I1,3,2,1 - Quality of attendance by support personnel. Indexes which establish averages are: I1,3,2,1,1 evaluation of the General Office and the Course's Secretary Office; I1,3,2,1,2 evaluation of the Registrar Office and Multi-attendance Office; I1,3,2,1,3 evaluation of the photocopy service; I1,3,2,1,4 - evaluation of the Library; I1,3,2,1,5 - evaluation of the Bursar's Office; I1,3,2,1,6 - evaluation of the Pharmacy school; I1,3,2,1,7 - evaluation of the Restaurant; I1,3,2,1,8 - evaluation of the Tourism Bureau; I1,3,2,1,9 evaluation of the bookshop; I1,3,2,1,10 evaluation of the coffee and fast-food shops.

I1,3,2,2 - Evaluation of the Infrastructure. Indexes which establish averages are: I1,3,2,2,1 - evaluation of the classrooms; I1,3,2,2,2 - evaluation of the parking lot; I1,3,2,2,3 - evaluation of traffic and car circulation on Campus; I1,3,2,2,4 evaluation of security on campus; I1,3,2,2,5 - evaluation of the Sports Complex (grounds, gymnasium, swimming-pool and Physical Training Unit); I1,3,2,2,6 - evaluation of the quality of computer apparatuses available for students (in the Library and in the Labs); I1,3,2,2,7 - evaluation of the availability of computer equipments for students; I1,3,2,2,8 - evaluation of support equipments in the classroom (overhead projectors, computers, videos etc).

I1,3,2,3 - Number of products/services. Indexes which establish averages are: I1,3,2,3,1 - evaluation of virtual service access offered; I1,3,2,3,2 - evaluation of the IHE web site; I1,3,2,3,3 - evaluation of the photocopy offices; I1,3,2,3,4 evaluation of the restaurant; I1,3,2,3,5 evaluation of the coffee and fast-food shops; I1,3,2,3,6 - evaluation of the 
pharmacy; I1,3,2,3,7 - evaluation of the Tourism Bureau; I1,3,2,3,8 - evaluation of the bookshop; I1,3,2,3,9 - evaluation of the Veterinary Hospital; I1,3,2,3,10 evaluation of clinics; I1,3,2,3,11 evaluation of the Health Unit; I1,3,2,3,12 - evaluation of cleanliness and maintenance of communal spaces.

I1,3,3 - Evaluation of professors. Indexes which establish averages are: I1,3,3,1 evaluation of professors' knowledge of contents; I1,3,3,2 - evaluation of lectures and abidance to teaching plan; I1,3,3,3 evaluation of didactic performance and clarity of contents in lectures; I1,3,3,4 evaluation of capacity in student motivation; I1,3,3,5 - evaluation of the relationship between professor and students in the classroom; I1,3,3,6 evaluation of lecture planning (punctuality and commitment to lecture timetable); I1,3,3,7 - general evaluation of the professor.

\subsection{Group II - Main Index of the technical and administrative community-I2.}

Satisfaction level, motivation with regard to activities developed by the technical and administrative personnel of the IHE and negative factors are identified so that strategies for better conditions could be defined. Justification of the above comprises the need of the pro-rectors and directors involved in the planning and administration of IHEs' technical and administrative quality to identify positive and negative factors. The group was divided into four subgroups: labor conditions, motivation, collaborators' satisfaction and selfevaluation. The group's standard was to obtain 90\% satisfaction and acceptance by the community. Environment is offline since it is directly linked to the activity of people who do not work precisely in the productive process (PALADINI, 2011). The technical and administrative group's four secondary indexes (labor conditions, motivation, collaborators' satisfaction and selfevaluation) are listed below.

I - Secondary Index of labor conditions - I2,1. When the institution's general conditions are evaluated with regard to the level of satisfaction in labor condition, the group's confidence level may be evaluated by calculating the eight indicators: I2,1,1 - equality of growth opportunities in the institution; I2,1,2 equality of treatment in the institution; I2,1,3 - the way the institution deals with the collaborators' personal problems; I2,1,4 - available equipments for the group's activities; I2,1,5 - cleanliness of the sector; I2,1,6 - security conditions within the sector; I2,1,7 - the dining room; I2,1,1 - attendance of the clinics in the Institution.

II - Secondary Index of motivation I2,2. A birds-eye-view of research with regard to the collaborators' motivation is aimed at. So that the general conditions of the institution could be evaluated with regard to the collaborators' motivation level for the development of their labor activities, the following indexes were employed: I2,2,1 - the capacity of learning new methods; I2,2,2 participation in activities proposed by the institution; I2,2,3 - capacity to suggest improvements in the sector; I2,2,4 responsibility for other functions in the institution.

III- Secondary Index of the collaborators' satisfaction - I2,3. A dimension for the collaborators' satisfaction in four fields is sought. So that the institution's general profile with regard to the collaborators' motivation level is evaluated, the group's confidence level should be evaluated, using the following indexes: I2,3,1 - internal security offered by the institution; I2,3,2 - equality of growth opportunities in the institution; I2,3,3 - fast-food shops or restaurants; I2,3,4 - parking lots. 
IV - Secondary Index of selfevaluation - I2,4. The index represents a bird-eye-view of the IHE with regard to the variable: the collaborators' personal evaluation. So that the institution's general profile with regard to the collaborators' self-evaluation is evaluated, the group's confidence level should be evaluated, using the following indexes: I2,4,1 - involvement and collaboration with the team in which one works; I2,4,2 - commitment to tasks; I2,4,3 commitment for the sector's improvement; I2,4,4 - the institution's image.

\subsection{Group II - Main Index of the external community - I3.}

The aim of the group is the identification the IHE's relationship levels with the external community in which it is inserted, the evaluation of the satisfaction index with the IHE and its services, the sensitiveness whether social responsibilities are perceived and the qualification of the entrepreneurship's idea on the IHE. Justification consists in the fact that when negative factors are identified, the strategies for the improvement of planning and management quality issues with the community could be defined. The group was divided into three sub-groups: relationship, social responsibility and the institution seen from the entrepreneurship's point of view. The group's standard was to obtain 90\% satisfaction and acceptance by the community. On line environment is directly linked to the market and to the perception of the clients' needs and conveniences (PALADINI, 2011). Standard for secondary indexes is calculated by the mean of tertiary indexes reaching at least $90 \%$.

I - Secondary Index of relationship I3,1. Aim: the identification of the IHE's relationship degree with the external community. Justification: the need for redirecting or improving activities developed with the external community through the Pro-Rectors' and Directors' offices involved. Environment: on line, relationship with the market and the perception of needs or conveniences of clients and consumers. The secondary index Relationship will be calculated by indexes: I3,1,1 - contribution of IHE in the city's cultural development; I3,1,2 contribution of the IHE in the city's economical development; I3,1,3 contribution of the IHE in the city's social development; 4) information on the IHE.

II - Secondary Index of social responsibility - I3,2. Aim: the identification of knowledge degree with regard to activities of social responsibility that the IHE undertakes. Justification: needs of the Pro-Rectors' and Directors' offices involved for society's response with regard to activities of social responsibility developed by the IHE. Environment: on-line, relationship with the market; off-line, institutional marketing. Secondary Index Social Responsibility will be calculated by indexes: I3,2,1 - social activities of the IHE; I3,2,2 - socially responsible IHE; I3,2,3 - social integration of the IHE with the community.

III - Secondary Index of the IHE for the entrepreneurship - I3,3. Aim: identification of the IHE's visibility degree for the entrepreneurship. Justification: needs of the Pro-Rectors' and Directors' offices involved for society's response with regard to the IHE's visibility for entrepreneurs with regard to courses provided by the IHE and their relationships with teaching, through the supply of jobs and economical activities to redirect or improve its visibility. Environment: online relationship with the market and offline for external marketing. Secondary Index IHE's Visibility for the 
entrepreneurship is calculated by the indexes: I3,3,1 - degree of knowledge with regard to IHE's courses; I3,3,2 level of engaging IHE's trainees; I3,3,3 level of satisfaction with regard to the experience of IHE's trainees in firms.

Calculation of indexes is undertaken by the arithmetical mean of indexes at each level. Table 1 shows the formulas and their calculation.

Table 1 - Formulas for the calculation of simple arithmetical averages of indexes at different levels.

\begin{tabular}{|c|c|}
\hline $\begin{array}{l}I=\frac{1}{N} \sum_{i=1}^{N} I_{i} \\
i=1, N \quad(1)\end{array}$ & $\begin{array}{c}\mathbf{I}_{i}=\frac{1}{\alpha_{i}} \sum_{j=1}^{\alpha_{i}} \mathbf{I}_{i, j} \\
\begin{array}{c}j=1, \alpha_{i} \\
(2)\end{array}\end{array}$ \\
\hline $\begin{aligned} \mathrm{I}_{\mathrm{i}, \mathrm{j}} & =\frac{1}{\beta_{\mathrm{j}}} \sum_{\mathrm{k}=1}^{\beta_{\mathrm{j}}} \mathrm{I}_{\mathrm{i}, \mathrm{j}, \mathrm{k}} \\
\mathrm{k} & =1, \beta_{\mathrm{j}}(3)\end{aligned}$ & $\begin{array}{l}\mathrm{I}_{\mathrm{i}, \mathrm{j}, \mathrm{k}}=\frac{1}{\gamma_{\mathrm{k}}} \sum_{\mathrm{l}=1}^{\gamma_{\mathrm{k}}} \mathrm{I}_{\mathrm{i}, \mathrm{j}, \mathrm{I}} \\
\mathrm{I}=1, \gamma_{\mathrm{k}} \\
(4)\end{array}$ \\
\hline $\begin{array}{c}\mathrm{I}_{\mathrm{i}, \mathrm{j}, \mathrm{k}, \mathrm{l}, \ldots, \mathrm{q}}=\frac{1}{\phi_{\mathrm{q}}} \sum_{\mathrm{l}=1}^{\phi_{\mathrm{q}}} \mathrm{I}_{\mathrm{i}, \mathrm{j}, \mathrm{k}, \mathrm{l},} \\
\mathrm{q}=1, \phi_{\mathrm{q}}(5)\end{array}$ & \\
\hline
\end{tabular}

\section{Analysis of Results}

Current research shows results by CPA of the IHE in 2011: 7,810 forms were sent to the students, with a response of 4,006 , or $51.3 \%$ of total number. As an example, the group of secondary indexes for students will be provided - I1,3, obtained by the formulas of Table 1 , when $i=1, j=3$ and $\mathrm{k}=1.3$, or rather, $\mathrm{I} 1,3, \mathrm{k}, \mathrm{l}, \mathrm{m}$ and their respective rates for vectors $l$ and $\mathrm{m}$.

$\mathbf{I}_{1,3}=\left\{\mathbf{I}_{1,3,1} ; \mathbf{I}_{1,3,2} ; \mathbf{I}_{1,3,3}\right\}$

$\mathrm{k}=1$

$\mathbf{I}_{1,3,1}=\left\{\mathbf{I}_{1,3,1,1} ; \mathbf{I}_{1,3,1,2} ; \mathbf{I}_{1,3,1,3}\right.$;

$\left.\mathbf{I}_{1,3,1,4} ; \mathbf{I}_{1,3,1,5} ; \mathbf{I}_{1,3,1,6} ; \mathbf{I}_{1,3,1,7}\right\}=$
\{60.13; 68.2; 73.18; 71.83; 65.68; $67.75 ; 57.63\}=66.34$

$\mathbf{I}_{1,3,1,1}=\left\{\mathbf{I}_{1,3,1,1,1} ; \mathbf{I}_{1,3,1,1,2} ; \mathbf{I}_{1,3,1,1,3} ;\right.$ $\mathbf{I}_{1,3,1,1,4} ; \mathbf{I}_{1,3,1,1,5} ; \mathbf{I}_{1,3,1,1,6} ; \mathbf{I}_{1,3,1,1,7}$; $\left.\mathbf{I}_{1,3,1,1,8} ; \mathbf{I}_{1,3,1,1,9} ; \mathbf{I}_{1,3,1,1,10}\right\}=\{79.3$; 75.5; 82.3; 74.8; 53.3; 42.9; 49.2; 56.3; 51.3; 36.4$\}=60.13$

$\mathbf{I}_{1,3,1,2}=\left\{\mathbf{I}_{1,3,1,2,1} ; \mathbf{I}_{1,3,1,2,2} ; \mathbf{I}_{1,3,1,2,3}\right\}$ $=\{74.7 ; 60.8 ; 69.1\}=68.20$

$\mathbf{I}_{1,3,1,3}=\left\{\mathbf{I}_{1,3,1,3,1} ; \mathbf{I}_{1,3,1,3,2} ; \mathbf{I}_{1,3,1,3,3} ;\right.$

$\left.\mathbf{I}_{1,3,1,3,4} ; \mathbf{I}_{1,3,1,3,5}\right\}=\{74.1 ; 78.2$; 67.3; 70.6; 75.7 $\}=73.18$

$\mathbf{I}_{1,3,1,4}=\left\{\mathbf{I}_{1,3,1,4,1} ; \mathbf{I}_{1,3,1,4,2} ; \mathbf{I}_{1,3,1,4,3}\right\}$ $=\{72.7 ; 73.3 ; 69.5\}=71.83$

$\mathbf{I}_{1,3,1,5}=\left\{\mathbf{I}_{1,3,1,5,1} ; \mathbf{I}_{1,3,1,5,2} ; \mathbf{I}_{1,3,1,5,3} ;\right.$ $\left.\mathbf{I}_{1,3,1,5,4}\right\}=\{76.5 ; 67.2 ; 61.8 ;$ $57.2\}=65.68$

$\mathbf{I}_{1,3,1,6}=\left\{\mathbf{I}_{1,3,1,6,1} ; \mathbf{I}_{1,3,1,6,2}\right\}=\{79.8 ;$ $55.7\}=67.75$

$\mathbf{I}_{1,3,1,7}=\left\{\mathbf{I}_{1,3,1,7,1} ; \mathbf{I}_{1,3,1,7,2} ; \mathbf{I}_{1,3,1,7,3}\right\}$ $=\{48.9 ; 51.7 ; 72.3\}=57.63$

$\mathrm{k}=2$

$\mathbf{I}_{1,3,2}=\left\{\mathbf{I}_{1,3,2,1} ; \mathbf{I}_{1,3,2,2} ; \mathbf{I}_{1,3,2,3}\right\}=$ $\{68 ; 66.45 ; 63.39\}=65.95$

$\mathbf{I}_{1,3,2,1}=\left\{\mathbf{I}_{1,3,2,1,1} ; \mathbf{I}_{1,3,2,1,2} ; \mathbf{I}_{1,3,2,1,3}\right.$; $\mathbf{I}_{1,3,2,1,4} ; \mathbf{I}_{1,3,2,1,5} ; \mathbf{I}_{1,3,2,1,6} ; \mathbf{I}_{1,3,2,1,7}$; $\left.\mathbf{I}_{1,3,2,1,8} ; \mathbf{I}_{1,3,2,1,9} ; \mathbf{I}_{1,3,2,1,10}\right\}=\{66.4$ 60.9; 81.9; 69.7; 70.6; 67.3; 56.3; $70 ; 66.6\}=68 ; 70.3$

$\mathbf{I}_{1,3,2,2}=\left\{\mathbf{I}_{1,3,2,2,1} ; \mathbf{I}_{1,3,2,2,2} ; \mathbf{I}_{1,3,2,2,3} ;\right.$ $\mathbf{I}_{1,3,2,2,4} ; \mathbf{I}_{1,3,2,2,5} ; \mathbf{I}_{1,3,2,2,6} ; \mathbf{I}_{1,3,2,2,7}$; $\left.\mathbf{I}_{1,3,2,2,8}\right\}=\{71.2 ; 67.7 ; 67.2 ; 66.9$; $58.4 ; 64 ; 63.1 ; 73.1\}=66.45$

$\mathbf{I}_{1,3,2,3}=\left\{\mathbf{I}_{1,3,2,3,1} ; \mathbf{I}_{1,3,2,3,2} ; \mathbf{I}_{1,3,2,3,3}\right.$; $\mathbf{I}_{1,3,2,3,4} ; \mathbf{I}_{1,3,2,3,5} ; \mathbf{I}_{1,3,2,3,6} ; \mathbf{I}_{1,3,2,3,7}$; $\mathbf{I}_{1,3,2,3,8} ; \mathbf{I}_{1,3,2,3,9} \quad ; \quad \mathbf{I}_{1,3,2,3,10}$; $\left.\mathbf{I}_{1,3,2,3,11} ; \mathbf{I}_{1,3,2,3,12}\right\}=\{78.3 ; 79.8$; $62.2 ; 66.7 ; 65.1 ; 66.9 ; 54.5 ; 68$; $47.3 ; 52 ; 48.1 ; 71.8 ; 78.3\}=63.39$ $\mathrm{K}=3$

$\mathbf{I}_{1,3,3}=\left\{\mathbf{I}_{1,3,3,1} ; \mathbf{I}_{1,3,3,2} ; \mathbf{I}_{1,3,3,3} ;\right.$ $\left.\mathbf{I}_{1,3,3,4} ; \mathbf{I}_{1,3,3,5} ; \mathbf{I}_{1,3,3,6} ; \mathbf{I}_{1,3,3,7}\right\}=$ \{85.2; 82.7; 78.2; 73.4; 80.3; 81.7; $80.6\}=80.30$

Therefore, $\mathbf{I}_{1,3}=\left\{\mathbf{I}_{1,3,1} ; \mathbf{I}_{1,3,2} ; \mathbf{I}\right.$ $\left.{ }_{1,3,3}\right\}=\{66.34 ; 65.95 ; 80.30\}=$ 70.86 
It should be noted that students' secondary index I1,3 shows that mean satisfaction rate of students is $70.86 \%$, which may be decomposed into: attendance provided at the IHE (66.34\%); infrastructure, products and services provided (65.95\%) and evaluation of IHE professors by students (80.30\%). Since expected standard for the group and its respective secondary indexes is the attainment of $80 \%$ rate in satisfaction and acceptance by a section of the community, a detailed identification of deficiencies should be undertaken.

It should be emphasized that the system allows the identification of these indexes at the level of each course, or rather, specific deficiencies with regard to these issues may be pin-pointed. The automatized system facilitates the individualized analysis of the professor group within the several indexes evaluated by different communities. Indexes may be crisscrossed at all levels, facilitating the discovery of new crisscrossed indexes. For instance, the graph in Figure 1a shows the index Content and Evaluations, obtained by linear regression between index I1,3,1,1,2 - evaluation of depth level in contents provided in the disciplines, and the index I1,3,1,1,3 - evaluation of exigency level of professors in tests. The correlation reached 95.6\%. Another example is shown in the graph of Figure $1 \mathrm{~b}$ obtained by linear regression between the index I1,3,1,2,1 - evaluation of knowledge of the course by the job market, and the index $I 1,3,1,2,2$ - evaluation of the insertion and rise in the job market of the future professional or the professional trained by the IHE. The correlation reached $95.3 \%$.

As a rule, the analyzed indexes provided haghly methods of former evaluation important information for planning to the IHEprThesses and the introduction of others.

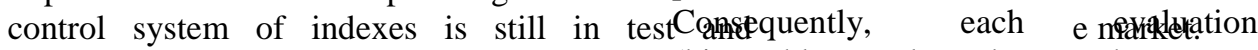
validation stage.

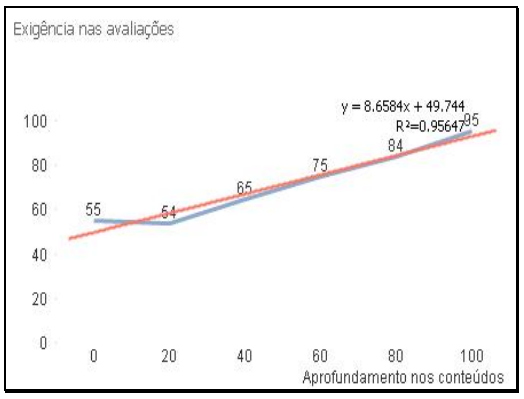

Fig.1a -Exigency in evaluations $x$ depth of contents

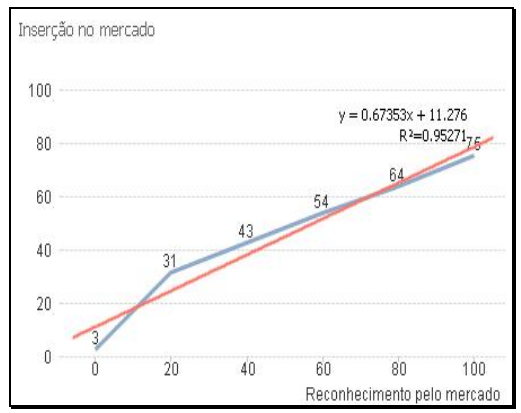

Fig. $1 \mathrm{~b}$ - Insertion in the market $\mathrm{x}$ acknowledgment by the market.

It should be emphasized that two important communities, Postgraduate Courses and Distance Learning, are still to be incorporated. Evaluation of the new communities will be provided in 2012 with two important main new indexes.

The system, featuring a process of constant improvement, constitutes one of the dimensions in university practice in so far as it boils down to a formation process in which each activity discovers and re-discovers the potentialities and weaknesses of the processes, methods and approaches. The process renovates and re-invents a continuous learning which is highly characteristic of the educational process. Such understanding allows the alteration of certain aspects (bimonthy, yearly and every three years - ENADE) reveals new discoveries in institutional assets to be shared and 
potentialized, and the eventual identification of weaknesses to be faced and superseded within the constant search for the construction of an IHE characterized by excellence.

It should also be emphasized that the system may be consolidated through the establishment of three control levels and quality management: operational, tactic and strategic levels (PALADINI, 2011). The Operational Level is linked to the production process and uses indexes of performance called productivity indexes, directly linked to in line quality. The Tactic Level is the organization as a whole and uses the support indexes, known as support indexes inserted within the off-line environment. The Strategic Level deals with the external relationships of the organization and is directly linked to the on-line environment. Its indexes are more comprehensive and may be called survival indexes.

Therefore, the system's final implementation will be undertaken when the new communities Postgraduate Courses and Distance Education are incorporated and thus new indexes introduced. At the end of the process, the complete system provides the control and the evaluation of the main areas of higher education in the Institution.

The calculation of indexes is another important factor. Table 1 shows that simple arithmetical mean is being applied to each level and index group. In the course of several analyses, Table 1 is being reformulated by introducing weighted arithmetic mean, with different weights to indexes with greater or less importance within the evaluated context.

\section{Conclusion}

The employment of a system based on the dimensions of IHE's internal evaluation undertaken by CPA and on the main official indexes of MEC provided improvements in the IHE's education quality. Even the partial use of the system in a dynamic form indicated the state of the indexes and provided an idea of the quality of the planning, management and systemic evaluation process of services provided. The same may be said with regard to teaching quality aimed at giving support to the IHE's strategic planning.

Data from the 2011 questionnaire and documental analysis are a reference that identifies the IHE's current situation and provides indexes that require a revision of some institutional presuppositions. Based on the analysis of results, the CPA may propose, when required, observations and recommendations to be incorporated by the IHE so that its activities, presuppositions, organizational structure, human and physical resources could be improved and innovated.

Collected systematized information will provide important subsidies to the university community at all levels and also to the external community. This is due to the fact that information is trustworthy and useful as far as they are used to potentialize the assets revealed and to correct the deficits detected.

\section{References}

[1] BOTTANI, N. The OECD educational indicators: purposes, limits and production processes. Prospects, Switzerland, v. 28, n. 1, p. 61-75, 1998.

[2] DIAS SOBRINHO, J. Avaliação educativa: produção de sentidos com valor de formação. Avaliação (Campinas), Sorocaba, SP, v. 13, n. 1, p. 193-207, mar. 2008.

[3] HOLDEREGGER, R. Estratégias para gestão acadêmica sustentável: estudo de Caso. 2009. 211f. Dissertação (Mestrado em tecnologia) - Centro Estadual de Educação 
Tecnológica Paula Souza, São Paulo, 2009.

[4] LEHFELD, N. A. S. et al. Reflexões sobre o processo de auto-avaliação institucional: o olhar de uma comissão própria de avaliação. Avaliação (Campinas), Sorocaba, v. 15, n. 1, p. 177-194, mar. 2010.

[5] MAINARDES, E.E; FERREIRA, J.J.; ONTINI, G.; Vantagens Competitivas em IES; Proposta e Teste de um Modelo. 2010, disponível em: http://www.dge.ubi.pt/investigacao/ TDiscussao/2010/TD06_2010.pdf. Acesso em: 02 setembro 2010.

[6] MHLANGA E. Composite indicators for educational quality management. 2008. Thesis (Dr. School Education) Faculty of Humanities, University of the Witwatersrand, Johannesburg, 2008.

[7] MORRISON, J. A. Total quality principles in education: a framework for restructuring. 1998. 138f. Thesis (Master of Education) - Institute for Studies in Education of the University of Toronto, Ontario, 1998

[8] PALADINI, E. P. Avaliação estratégica da qualidade. 2. ed. São Paulo, SP: Atlas, 2011.

[9] PRATASAVITSKAYA, H.; Institutional quality management: a meta-analysis of theories and approaches. Master of Philosophy in Higher Education - Faculty of Education, Institute for Educational Research University of Oslo, May 2008.

[10] TAVENAS, F. Quality assurance: a reference system for indicators and evaluation procedures. Brussels, Belgium: Report published ELU- European University Association, 2003. 